\title{
Blepharophimosis, eczema, and growth and developmental delay in a young adult: late features of Dubowitz syndrome?
}

\author{
Stanislas Lyonnet, Gérard Schwartz, Gérard Gatin, Yves de Prost, Arnold Munnich, \\ Martine Le Merrer
}

Behavioural problems such as carelessness and poor compliance were also noted. His parents and teachers reported that independence and self-help skills were considerably delayed, especially eating (acquired at the age of 14 years).

At the time of examination (19 years old), height was $146 \mathrm{~cm}$, weight $30 \mathrm{~kg}$ (below $3 \mathrm{rd}$ centile), and head circumference $56 \mathrm{~cm}$ (mean value for age $55 \mathrm{~cm}$ ). He had a small face and a high pitched, hoarse voice giving an impression of old age. Characteristic dysmorphic features included a high forehead with flat supraorbital ridges, mild hypertelorism and telecanthus, asymmetrical ptosis with short palpebral fissures (blepharophimosis), a broad nose, low set, posteriorly rotated, and anteverted ears, and micrognathia (figure). He had sparse, fine hair with scanty eyebrows. His skin was dry with many eczematous and excoriated lesions on the face and neck. The skin was wrinkled, especially on the face and palms, which looked like premature ageing. The teeth were carious. Bilateral cryptorchidism was present but pubertal status was normal. Abdominal, skeletal, ophthalmological, and neurological examinations were otherwise normal.

Echocardiography showed mitral valve prolapse (without any functional sign). Skeletal radiographs were normal with respect to bone density and morphological features. The following investigations were normal: white and red blood cell count, serum transaminases, creatine kinase, plasma immunoglobulins, amino acids, lactate/pyruvate molar ratios, gas chromatography-mass spectrometry of the urine, and pituitary and thyroid hormone investigations. His karyotype was found to be normal using $G$ and $R$ banding techniques. Increased chromosome breakage and sister chromatid exchange were not investigated. $67 \mathrm{~cm}(-3 \mathrm{SD}), 110 \mathrm{~cm}(-3.3 \mathrm{SD}), 131.5 \mathrm{~cm}$ $(-5 \mathrm{SD})$, and $146 \mathrm{~cm}(-5 \mathrm{SD})$ at $1,8 \frac{1}{2}, 16 \frac{1}{2}$, and 19 years of age respectively. Closure of the cranial sutures was delayed. Bone age was delayed but normal in relation to statural age (for example, chronological age $8 \frac{1}{2}$ years, statural age 5 years, bone age 5 years). Eczematous lesions were noted from the age of $1 \frac{1}{2}$ months and were still present at the time of examination. Mental retardation was mild to moderate. There was a significant delay in gross motor developmental milestones (he first walked alone at 3 years) and fine motor abilities (unable to climb stairs unaided at 14 years). $\mathrm{He}$ followed regular classes with great difficulty and poor results. He had borderline capability with respect to language and memory, and delayed development in abstract reasoning.

\section{Discussion}

The association of short stature with eczematous skin eruption, dysmorphism, ptosis, blepharophimosis, developmental problems, high pitched voice, and cryptorchidism in our patient is consistent with the diagnosis of Dubowitz syndrome. ${ }^{1}$ Since the original description of this syndrome, several cases have been reported ${ }^{2-5}$ and autosomal recessive inheritance of the disease has been proposed.

However, several clinical features are unusual and make the diagnosis of Dubowitz syndrome controversial in our patient. First, 


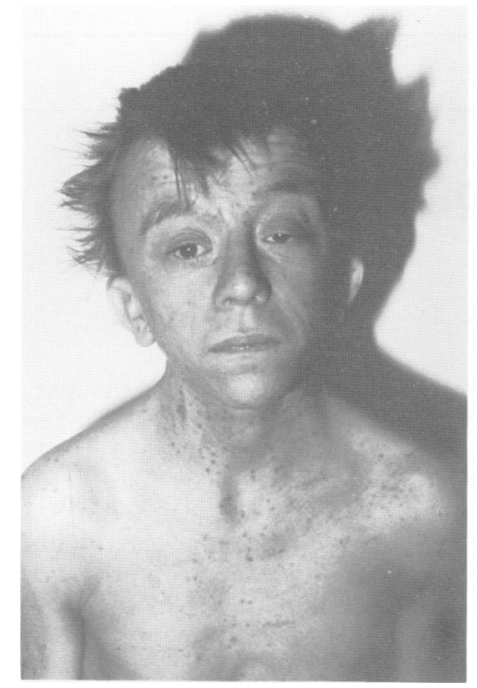

The proband, aged 19 years.

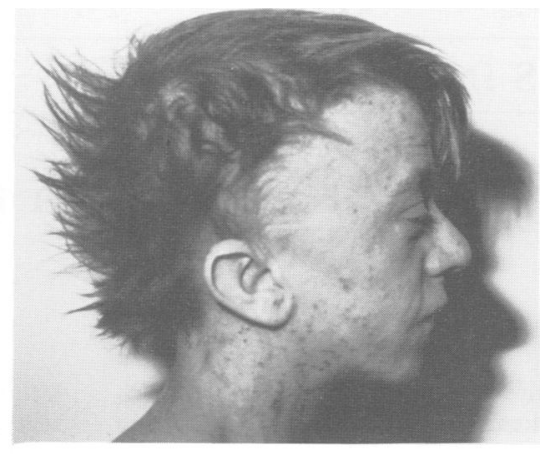

two major features of the syndrome are missing, namely microcephaly and intrauterine growth retardation. ${ }^{56}$ However, Levin et al have recently reported on a case of Dubowitz syndrome where these two features were missing. Similarly, birth weight was normal in the patients reported by Wilroy $e t a l^{3}$ and Orrison et $a .^{8}$ Secondly, the dysmorphic features in our patient, although consistent with Dubowitz syndrome, were slightly different from the original descriptions and published photographs. For instance, the contours of the face were elongated, the nasal bridge was normally prominent, and the ears were posteriorly rotated. Thirdly, the eczematous skin lesions, which usually decrease by the age of 2 to 4 years, were still present when the patient was examined, which might explain his aged look.

Yet, in spite of these discrepancies, Dubowitz syndrome is still the most likely diagnosis in our patient especially as other known syndromes could be excluded. Pregnancy history made the diagnosis of fetal alcohol syndrome unlikely. Other disorders with blepharophimosis, including the Marden-Walker and Schwartz-Jampel syndromes, could also be ruled out, based on physical and neurological examination. Cardiofaciocutaneous syndrome was considered but there was no pterygium colli, hypertelorism, or downward slanting palpebral fissures. In addition, neither significant cardiac defect nor follicular keratosis was observed in our patient. Syndromes with premature ageing, including progeria or progeria-like syndromes, mandibuloacral dysplasia, and Werner syndrome, were considered, but their cutaneous features are different and consist of a very thin skin with prominent vessels and hyperpigmented mottling. In our patient, however, the cutaneous changes included non-pigmented cicatricial lesions and a dry and squamous skin, related to the evolution of severe eczema.

Obviously, more information on the clinical outcome of Dubowitz patients aged over 12 years is needed to draw any conclusion regarding phenotypic variation, especially as a broad spectrum of clinical phenotypes has already been reported. ${ }^{910} \mathrm{We}$ can only suggest, along with Fryns et al, ${ }^{11}$ that the strikingly aged appearance of our patient might not be only related to growth failure and eczematous skin lesions, but may also be regarded as a consistent feature of Dubowitz syndrome. Since there is no specific test for this syndrome, the diagnosis remains tentative.

In conclusion, the present case emphasises the need for more information about the clinical outcome of these patients and suggests that one must be cautious when confirming or rejecting the diagnosis of Dubowitz syndrome, especially when the proband is first seen in early adulthood.

We are grateful to Monique Poussière and Alan Strickland for their help in preparing this manuscript.

1 Dubowitz V. Familial low birthweight dwarfism with an unusual facies and a skin eruption. $\mathcal{f}$ Med Genet 1965;2:12-17.

2 Opitz JM, Pfeiffer RA, Hermann JP, Kushnick T. Studies of malformation syndromes of man. XXIVB. The Dubowitz syndrome. Further observations. $Z$. Kinderheilkd 1973;116:1-12.

3 Wilroy RS Jr, Tipton RE, Summitt RL. The Dubowitz syndrome. Am $\mathcal{f}$ Med Genet 1978;2:275-84.

4 Moller KT, Gorlin RJ. The Dubowitz syndrome: a retrospective. f Craniofac Genet Dev Biol 1985;suppl 1:283-6.

5 Küster W, Majewski F. The Dubowitz syndrome. Eur $\mathcal{f}$ Pediatr 1986;144:574-8.

6 Winter RM. Dubowitz syndrome. $f$ Med Genet 1986;23:11-13.

7 Levin SW, Warren P, Greenstein RM, Rose SR, Mulvihill JJ. Severe blepharophimosis, developmental retardation, and multiple defects: atypical Dubowitz syndrome? Dysmorphol Clin Genet 1987;1:86-9.

8 Orrison WW, Schnitzler ER, Chun RWM. The Dubowitz syndrome: further observations. Am $f$ Med Genet 1980;7:155-70.

9 Parrish JM, Wilroy RS Jr. The Dubowitz syndrome: the psychological status of ten cases at follow-up. $A m \mathcal{F} \mathrm{Med}$ Genet 1980;6:3-8.

10 Ilyina HG, Lurie IW. Dubowitz syndrome: possible evidence for a clinical subtype. Am $\mathcal{f}$ Med Genet 1990; 35:561-5.

11 Fryns JP, Farbry G, Willemyns F, van den Berghe $H$. The Dubowitz syndrome in a teenager. Am $\mathcal{F}$ Med Genet 1979;4:345-7. 